\title{
Os estudos críticos da religião e do secularismo: virada ou paradigma?
}

The Critical Studies of Religion and Secularism: Turn or Paradigm?

Les études critiques de la religion et de la sécularisation : tournant

ou paradigme?

Bruno Reinhardt

\section{(2) OpenEdition}

\section{Journals}

\section{Edição electrónica}

URL: http://journals.openedition.org/rccs/11148

DOI: $10.4000 /$ rccs. 11148

ISSN: 2182-7435

\section{Editora}

Centro de Estudos Sociais da Universidade de Coimbra

Edição impressa

Data de publição: 1 dezembro 2020

Paginação: 97-120

ISSN: 0254-1106

\section{Refêrencia eletrónica}

Bruno Reinhardt, "Os estudos críticos da religião e do secularismo: virada ou paradigma? », Revista

Crítica de Ciências Sociais [Online], 123 | 2020, posto online no dia 15 dezembro 2020, consultado o 21 dezembro 2020. URL : http://journals.openedition.org/rccs/11148; DOI : https://doi.org/10.4000/

rccs. 11148

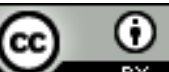




\title{
BRUNO REINHARDT
}

\section{Os estudos críticos da religião e do secularismo: virada ou paradigma?}

\begin{abstract}
Neste artigo proponho uma revisão da recente virada crítica nos estudos da religião e do secularismo. Revisito alguns aspectos da abordagem genealógica e antropológica de Talal Asad para a religião, o secular e o secularismo, e destaco duas linhas de investigação por ela estimuladas: o estudo comparativo dos secularismos realmente existentes e o estudo simétrico de fricções e controvérsias entre o conceito secular de religião e as tradições por ele englobadas. Esse sobrevoo me servirá de base para debater se o recente rearranjo do lugar da religião na academia indicaria uma "virada" ou uma "mudança paradigmática".
\end{abstract}

Palavras-chave: estudos críticos da religião; poder político e religião; secularização; Talal Asad.

\section{Introdução}

O problema das fronteiras entre a religião e a ordem secular tornou-se um dos temas mais candentes no debate político do século XXI. O sentimento difuso de ressurgimento da religião incitou, entre acadêmicos, uma virada crítico-reflexiva sobre as teorias da secularização herdadas do século XIX, incluindo o conceito de religião nelas embutido. Chamarei esse conjunto heterogêneo de trabalhos de "estudos críticos da religião e do secularismo", nome que, apesar de longo, me permite evitar os meandros do debate em torno do conceito de pós-secular (Gorski et al., 2012). Os estudos críticos da religião e do secularismo assumiram uma série de versões disciplinares e transdisciplinares. Sua expansão se deu através do resgate de autores antes marginalizados (como Carl Schmitt), de revisões por parte de autores clássicos (Habermas, 2007; Berger, 1999), e do estabelecimento de novos autores-chave, como José Casanova, Charles Taylor e Talal Asad.

Meu objetivo neste artigo é realizar uma apresentação panorâmica desse campo de estudos tomando como base o trabalho do antropólogo Talal Asad. Destaco a singularidade da sua abordagem genealógica e 
antropológica para a religião, o secular e o secularismo, o que me levará a distinguir duas linhas de investigação estimuladas por sua obra: o estudo comparativo dos secularismos realmente existentes e o estudo simétrico de controvérsias e incomensurabilidades entre o conceito secular de religião e as tradições por ele englobadas. Em diálogo com o tema do dossiê no qual este artigo se insere, concluo avaliando se o recente rearranjo do lugar da religião na academia indicaria uma "virada", uma "mudança paradigmática" (Kuhn, 1998), ou outro tipo de intervenção.

\section{Talal Asad entre os estudos críticos da religião e do secularismo}

Apesar de sua heterogeneidade, pode-se dizer que os estudos críticos da religião e do secularismo são apoiados em um axioma comum: a crítica a definições da ordem secular em termos de subtração (Taylor, 2007) ou ausência (Calhoun, 2012) de religião. De acordo com a tese clássica da secularização, a religião ocupava um amplo lugar na sociedade pré-moderna e passou a perder relevância social e a se retrair até assumir uma dimensão privada e funcionalmente discernível, deixando todo o resto intacto. Essa visão assume uma dimensão moral e política aguda nas filosofias da história do século XIX ao representar a secularidade enquanto "libertação da religião", base do tempo vazio homogêneo (progressista ou historicista) que caracteriza a modernidade ocidental (Chakrabarty, 2000).

A crítica do secularismo enquanto negatividade visa sobretudo problematizar seu registro abstrato ao dotá-lo de força normativa. Isso implica em entender a secularidade não mais como o desvelamento de um humanismo exclusivo (Taylor, 2007) antes oprimido ou ofuscado pela religião, mas como resultante de diversos processos históricos situados e relacionais de reformulação da subjetividade, da temporalidade, do político e do ético, que inclui e não apenas se afasta do conceito de religião. Isso se reflete em argumentos cada vez mais comuns hoje, como "o secularismo de Estado não implica simplesmente a retirada do Estado dos assuntos religiosos, [...] ele consiste no Estado assumir o papel de regulador último das afiliações religiosas e árbitro de demandas religiosas" (Chatterjee, 2010: 527; itálico no original $)^{1}$ ou que a compreensão da secularidade enquanto um "desenvolvimento desconectado da religião, neutro e universal da modernidade europeia" (Göle, 2010: 43) seria uma construção ideológica. Esse axioma comum gerou projetos bastante distintos.

Casanova $(1994,2008)$ questiona a identificação entre teoria da secularização e teoria da modernização, e pluraliza a secularidade ao acoplá-la a

\footnotetext{
${ }_{1}^{1}$ Todas as traduções apresentadas são da minha responsabilidade.
} 
diversas histórias de formação do Estado-nação, estimulando análises comparativas da relação entre religião e sociedade civil. Taylor (2007), por sua vez, evita lidar com a secularidade em seus aspectos institucionais, relativos ao Estado (o que chama de secularidade 1), ou em termos do decrescimento ou não da adesão religiosa (secularidade 2). Seu foco recai sobre o que chama de secularidade 3, ou seja, as transformações nas "condições da crença" específicas ao que chama de "Atlântico Norte" de um self pré-moderno "poroso" a agentes não humanos para um self "insulado", em que "existe a possibilidade de tomar distância, desengajar-se de tudo fora da mente" (ibidem: 55).

A abordagem de Asad distingue-se por sua natureza especificamente antropológica, caracterizada pela "comparação de conceitos embutidos [embedded concepts] (representações) entre sociedades localizadas diferencialmente no tempo e no espaço" (Asad, 2003: 17). Esse diferencial espaço-temporal é abordado não apenas etnograficamente, mas também através do método genealógico, que adiciona ao instrumental antropológico "um modo de trabalhar retrospectivamente a partir do presente e na direção das contingências que se agregaram de modo a legar nossas certezas" (ibidem: 16). Asad expõe as dificuldades de projetos reformistas como os de Casanova e Taylor ao visibilizar o caráter formativo do vínculo entre as teorias da secularização e do desencantamento e a produção política (concreta e representacional) do Ocidente. O próprio conceito de crítica deixa aqui de significar uma readequação epistemológica ou empírica dessas teorias e passa a buscar o desvelamento de seu vínculo com estruturas de normatividade amplas. Asad inicia sua antropologia do secularismo a partir de seu ponto cego: a pergunta sobre o que é "o secular", o modo com que se refere às condições epistemológicas e (histórico-)ontológicas de possibilidade do secularismo enquanto doutrina política.

O projeto de Asad assemelha-se ao de Taylor quando este pretende abordar o secular não através da secularização, mas através da religião, conceito pouco problematizado por Casanova. No entanto, Asad diverge de Taylor quando evita partir de uma definição substancial de religião, como sentimento de "plenitude" (Taylor, 2007: 8). Para Asad, o secular enquanto estrutura de poder-conhecimento-sensibilidade opera através de cadeias de oposições e relaciona-se com o religioso de maneira interdependente. Assim, tornou-se comum atribuir à crítica de Asad a pecha de nominalista (Robbins, 2003). Contrapondo-se explicitamente a essa interpretação, Asad (2012: 39; itálico meu) argumenta que:

A razão pela qual defendo não haver uma concepção universal de religião não é que fenômenos religiosos sejam infinitamente variados. Nem que algo como a religião 
não exista. É que definir algo é sempre um ato histórico, e quando definições são empregadas, elas fazem coisas diferentes em diferentes tempos e circunstâncias, e respondem a diferentes questões, necessidades, pressões.

Isso seria igualmente válido para seu "gêmeo siamês" (Asad, 2012:39), a secularidade. Para Asad, o maior problema com definições universais de religião não estaria em sua falta de coerência conceitual ou base empírica, nem mesmo na ausência de termos equiparáveis em línguas não-ocidentais, mas em como elas nos distraem da inevitável interpenetração histórica entre representações e intervenções (Hacking, 2000). Assim, diferente de relativista ou nominalista, a abordagem de Asad para as fronteiras sociais seria sobretudo pragmática, assumindo, assim como MacIntyre (1984: 61), que "não deveria haver duas histórias, uma da ação política e moral e uma da teorização política e moral, porque não há dois passados, um povoado somente por ações e outro somente por teorias".

A divergência com a abordagem de Taylor no tocante à definição de religião é evidente, mas também em relação ao projeto de Casanova de reter da tese clássica da secularização o axioma da diferenciação estrutural entre religião e política (Asad, 2003: 181-204). O conceito de desprivatização da religião quer reajustar de maneira epistemológica os limites da religião na ordem secular sem necessariamente se perguntar como a publicidade [publicity] religiosa é ativada, enquanto Asad está mais interessado em elevar os processos mesmos de regulação de fronteiras a objetos de investigação: "Minha preocupação é com o processo através do qual fronteiras são estabelecidas e vêm a ser definidas como modernas [...] Minha impressão é que essas questões não interessam a Casanova" (Asad, 2006: 209, itálico no original). Para isso, é essencial reconhecer que "o discurso moderno sobre a religião ou as religiões foi, desde a sua origem, um discurso da secularização" (Masuzawa, 2005: 20), articulando-se de diversas formas com novas tecnologias de regulação e governo da vida, incluindo a estabilização mentalista da religião em torno do conceito de "crença" (Asad, 1993).

\section{Uma história de "gêmeos siameses"}

O problema da transição de um contexto europeu medieval, em que o secular referia-se a um componente interno à tradição cristã, para uma configuração moderna, em que a religião refere-se a um domínio interno e discernível da ordem secular, é obviamente complexo. De forma extremamente sumária, diria que a construção secular da religião se deu sobretudo através de encontros históricos que geraram a quebra do poder autoritativo de tradições - hoje enquadradas como religiosas - de se autodefinirem, 
logo, autogovernarem. Esse processo de formação da religião como um equivalente geral apto a nivelar diversas tradições, formas de vida e regimes de autoridade ocorre em paralelo à formação do secularismo não como um "quadro imanente" (Taylor, 2007), mas como uma "mediação transcendente" (Asad, 2003: 5), capaz de recodificar diferenças substanciais em termos de "diversidade" no interior de uma categoria unitária.

Historiadores que refletiram sobre as transformações da categoria religião (Cantwell-Smith, 2006; Dubuisson, 2003; Nongbri, 2013) demonstram que seu uso romano e cristão antigo, em latim, oscilava entre "religar", "reler" e "ser cuidadoso", referindo-se sobretudo à adequação do sujeito a um aparato prescritivo. ${ }^{2}$ Não por acaso, o uso do léxico da religião na Europa pré-secular era sobretudo como adjetivo e advérbio, e não como substantivo, sendo o monge o sujeito "religioso" arquetípico. Pode-se dizer que "religião" nesse contexto tinha um sentido mais ético do que epistemológico, indicando sobretudo performances rituais - lembrando que o uso pré-secular do termo "ritual" não distinguia entre ações simbólicas extraordinárias e ações instrumentais ordinárias (Asad, 1993: 55-81). Em um contexto medieval, rituais eram os livros e códigos autorizados que organizavam a liturgia e o catequismo nas igrejas e a vida nos mosteiros. Esses códigos e dispositivos eram prescritivos, logo detinham pouco do que entendemos hoje como "simbólico" (Geertz, 1989). ${ }^{3}$

Assim como a religião, o secular também tem uma história pré-moderna eclipsada pela secularização (Koselleck, 2014). No contexto medieval, saeculum significava a dispensação temporal pré-escatológica de um mundo saturado pela historicidade bíblica, assim como o domínio espacial externo aos mosteiros, submetido à lei canônica e natural. Por sua vez, "secularização" era o processo de saída da vida monástica para a vida canônica, e em um contexto pós-Reforma Protestante, de fragmentação da autoridade eclesial, passa também a significar a transferência de propriedade eclesiástica para proprietários laicos. Antes uma parte constitutiva da gramática teológica, o secular transmuta-se em o outro da religião, entendida como uma posição epistemológica, restando à "sociologia do erro" do século XIX explicar a sua curiosa permanência.

A abordagem de Asad para a relação entre protestantismo e modernidade difere de autores weberianos como Louis Dumont e Marcel Gauchet, que entendem o secular como um desenvolvimento dialético de propriedades

\footnotetext{
2 Por motivos de espaço, ignoro as importantes distinções entre os usos clássicos e cristãos do termo.

3 Sobre as dificuldades de se traduzir a terminologia medieval para a gramática epistemológica da “crença”, ver Weltecke (2008).
} 
cosmológicas do cristianismo, como sua articulação entre transcendência e imanência. Milbank (2006: 95) chama essa corrente teórica de "metanarrativa liberal protestante", e argumenta que ela "falha em ver individualismo, fidelismo, e eticização kantiana como mudanças contingentes na doutrina e ethos cristãos, projetando essas coisas na origem do cristianismo e mesmo no Velho Testamento". Direta ou indiretamente, essa metanarrativa tende a dotar o cristianismo ocidental de excepcionalismo moral ao minimizar sua historicidade política. Por exemplo, a demolição literalista do aparato de governo Católico Romano operada por Lutero, Calvino, Zwinglio e outros reformistas está longe de fazê-los baluartes da "liberdade de consciência" e do "humanismo", como querem apologistas do excepcionalismo ocidental (Simpson, 2007). A Reforma está imbricada com a secularidade moderna não por causa de valores compartilhados, como a tolerância, mas justamente por ter funcionado como um estopim para as Guerras de Religião.

De acordo com Taylor (1998: 32), "o ponto de origem do secularismo moderno ocidental foram as Guerras de Religião; ou, melhor, a busca fatigante e aterrorizada por [...] um chão comum para a coexistência de cristãos de diferentes persuasões confessionais". Trata-se de um tortuoso processo teológico-jurídico em que "a heresia tornou-se alteridade" (DeCerteau, 1992: 155). Essa alteração qualitativa erodiu a prerrogativa do cristianismo de se autodefinir e reconfigurou radicalmente o sentido de religião, demandando um novo tipo de sujeito, descolado ontologicamente das formas tradicionais autorizadas de saber e disciplinamento através de uma cisão entre foros interno e externo. A pacificação da religião através de sua transvaluação jurídica foi alheia ao projeto dos reformistas protestantes, mas elaborou sobre a sua noção imaterialista de fé.

Outro importante componente da narrativa oficial da secularização a ser matizado é a representação do Tratado de Vestfália (1648) como uma solução secular para a intolerância religiosa. Enquanto base do sistema geopolítico moderno, Vestfália certamente significou a consolidação de uma nova concepção de autoridade política, fundada no Estado-nação e no princípio de soberania, incluindo tensões teopolíticas estruturais (Lefort, 1991; Schmitt, 1996). Porém, sua consequência imediata não foi a secularização do Estado ou da sociedade, mas a territorialização da religião via confessionalização (cuius regio eius religio) (Krasner, 1999). Nesse sentido, a oposição doméstico/internacional, que possibilitou a alienação da Igreja Católica das relações internacionais, além de conversões e migrações forçadas, foi certamente mais relevante para esse paradigma do que a divisão liberal entre público/privado. A absorção do poder religioso-secular pelos soberanos de fato gerou tensões com as ordens eclesiásticas que animaram 
a eventual separação entre religião e Estado, o que ocorreu muito tardiamente (aprofundarei este tema na próxima seção).

O uso da divisão liberal entre privado e público enquanto tecnologia de "regulação da aversão" (Brown, 2006) já era, no entanto, mobilizado no século XVII por autores como John Locke (2014 [1689]) a partir da noção deísta de "religião natural". O axioma de que a crença não pode ser imposta pelo Estado, já que se assentaria na liberdade de consciência (logo, o máximo que essa imposição geraria seria uma "crença inautêntica"), é de fato a primeira defesa sistemática da liberdade religiosa contra a intervenção estatal. Mas essa estabilização ontológica da religião no chamado "foro interno" individual (uma versão originária do que Taylor chama de "self insulado") visava sobretudo legitimar a intervenção do Estado sobre o "foro externo" dos cidadãos. O importante aqui, em suma, é menos a definição de liberdade de consciência, do que a sua submissão estrutural (e "porosa") a uma nova noção de "dano", de base empirista, cuja definição é controlada pelo soberano e que expropria a Igreja de seu poder pedagógico sobre o "foro externo" dos cidadãos (McClure, 1990).

Inicialmente restrito ao cristianismo europeu, o processo de abstração da "religião" de sua estrutura autorizada passa a globalizar-se a partir do século XIX. Esse fenômeno reflete as ressonâncias do modelo político anticlerical proposto pela Revolução Francesa na Europa e o avanço sem precedentes da secularização científica do conhecimento, que inaugura a possibilidade de se avaliar e criticar "a religião" em geral, a partir de posições empiristas e históricas. É nesse contexto que se dá o primeiro uso do termo "secularismo", por George Holyoake, em 1846, um projeto missionário de erradicação da superstição na Inglaterra através das Sociedades Seculares. Categorias como civilização e progresso, típicas das filosofias da história do século XIX, reorganizavam um tempo esvaziado da historicidade cristã pelo alto criticismo bíblico (Frei, 1974) em torno de teleologias históricas seculares que mimetizavam a história da salvação em termos antropocêntricos (Koselleck, 2014). Anticlerical em casa, esse projeto histórico era matizado nas colônias através das "missões civilizadoras", que tomavam o cristianismo como um meio pedagógico-moral de aceleração do progresso (Comaroff e Comaroff, 1997).

O século XIX é o berço da tese sociológica da secularização, assim como dos estudos das "religiões mundiais" (Masuzawa, 2005), que inflaram o genus religião com novos "ismos", associados primeiro às religiões semíticas, como o judaísmo e o islamismo (já vigentes no século XVIII), e eventualmente as religiões orientais, como o hinduísmo, o budismo e o xintoismo (van der Veer, 1994). A matriz romântica desse novo paradigma faz-se notar, 
por um lado, por seu suporte na filologia do tronco indo-europeu, que alimentou a "renascença oriental" (Schwab, 1984) na Europa; e por outro, pela postulação de uma experiência religiosa basilar, articulada publicamente por uma variedade de sistemas simbólicos historicamente situados. A separação entre corpo e mente que caracteriza as abordagens culturalistas da religião estaria assim assegurada.

A origem da retórica moderna da experiência - que ecoa com o conceito de "plenitude" (Taylor, 2007) - é atribuída a Friedrich Schleiermacher, que se opôs às vertentes materialistas do Iluminismo através da "estratégia protetiva" romântica de insular a verdade religiosa através de uma divisão ontológica entre o lógico-indutivo e o estético, o natural e o espiritual (Proudfoot, 1985). Sob essa ótica, a racionalidade da religião seria a racionalidade dos poetas (Asad, 2003:21-66), irredutível à linguagem propositiva e cientificamente falseável das crenças. A religião torna-se, assim, logicamente invulnerável ao se atualizar através de símbolos de uma inefável experiência pré-linguística ("o sagrado", de Rudolph Otto ou a "experiência religiosa" de William James). Esse conceito de experiência fundamentou o estudo comparativo de orientalistas como Max Muller, mas também gerou efeitos de looping no próprio campo religioso, que se globalizava e nacionalizava simultaneamente, tornando-se base da categoria contemporânea de espiritualidade (van der Veer, 2009). ${ }^{4}$

No caso das religiões politeístas de África, a ausência de livros sagrados, aptos a projetar sobre essas práticas o modelo canônico do cristianismo, é suprida pelo trabalho antropológico de organizá-las em textos culturais altamente coerentes. David Chidester (1996) demonstra que, antes de serem "pacificados", os povos da África austral aparecem no discurso europeu como "sem religião". Após serem submetidos ao aparato colonial, passam curiosamente a manifestar uma exuberância de sistemas religiosos, cujo complexo simbolismo é reconstituído e celebrado por missionários e antropólogos coloniais, salvo práticas avessas à sensibilidade liberal seletivamente isoladas do genus religião e reguladas enquanto "costumes bárbaros". Assim como no caso orientalista, a celebração antropológica da diversidade "religiosa" africana é continuada por acadêmicos, Igrejas, Estados e elites autóctones após as independências (Shaw, 1990; Comaroff e Comaroff, 1997). Como parte de Estados soberanos que herdaram o modelo missionário e colonial bifurcado entre cidadãos modernos e sujeitos tradicionais

\footnotetext{
${ }^{4}$ Sharf (1998: 100) comenta que "simplesmente não há evidência de uma contrapartida Hindu para a retórica da experiência antes do período colonial" e que as palavras japonesas para experiência (keiken e taiken) "são ambas neologismos cunhados na era Meiji (1868-1912) por tradutores de obras de filosofia Ocidental” (ibidem: 102).
} 
(Mamdami, 1996), o secular passa a englobar o direto costumeiro, que se distingue de maneira instável do campo propriamente religioso (Atiemo, 2013).

Minha intenção com este rápido resumo foi fundamentar historicamente o instrumental analítico proposto por Asad: antes de oposta ao secular, a categoria moderna de religião emerge como seu gêmeo siamês; e o secularismo, a doutrina política do secular, é sobretudo uma statecraft, uma técnica de governo que negocia e estabelece fronteiras. Essa abordagem retém um forte senso de interdependência geopolítica, além de uma salutar consciência acerca da contingência dos processos de definição e legitimação.

\section{A variedade dos secularismos realmente existentes}

Tomar o secular e o religioso como categorias germanas não significa reduzir o secular a uma máscara ou reconfiguração do religioso, como o fazem Hayes (1960), Schmitt (1996) ou Lowith (1990). Essa perspectiva simplesmente inverte a lógica do argumento secularista clássico da oposição para a identificação, logo perde de vista a relação regulatória concreta entre grupos definidos e/ou autodefinidos como religiosos e o estado secular. De acordo com Asad, o secularismo "não é apenas uma resposta intelectual à questão relativa à paz social e tolerância duradouras. Ele é uma atualização concreta [enactement] pela qual um meio político (a representação dos cidadãos) redefine e transcende práticas diferenciadoras do self articuladas através de classe, gênero e religião" (Asad, 2003: 5). O fato do secular ser uma epistemologia e uma ontologia altamente difusas e do secularismo ser um modo de governo discernível, assentado no princípio de soberania, nos ajuda a entender a pluralidade de formas concretas engendradas pela secularização. Esse pressuposto encoraja o estudo comparativo dos secularismos realmente existentes.

Em seu livro sobre o secularismo nas relações internacionais, Hurd (2007) promove uma tipologia dupla entre laicismo e secularismo judaico-cristão. O laicismo remete à tradição jacobina anticlerical, que representa a modernização como sendo a superação política e moral de tradições metafísicas do passado. Ele isola a religião da autoridade política, privatiza suas lealdades e promove o declínio de sua relevância social através de um "processo coercitivo em que os poderes legais do Estado, os poderes disciplinares da família e da escola, e os poderes persuasivos do governo e da mídia são usados para produzir um cidadão secular que consente em manter a religião no domínio privado" (Chatterjee, 2006: 60). Seu componente prescritivo é abstraído pelo campo acadêmico através das teorias da modernização e sua vinculação unilinear entre modernidade, desenvolvimento e declínio 
da religião. O paradigma laicista foi implementado na França de maneira modelar, mas também na China moderna, no Kemalismo turco, na União Soviética, entre outros. Seu caráter agonístico tende a gerar religiões civis militantes, incluindo ateísmos de Estado (Luehrmann, 2011).

O secularismo judaico-cristão, por sua vez, legitima-se através de uma constante reorientação para as continuidades com essa matriz religiosa-cultural. Seu objetivo não é rejeitar a religião em nome de uma ética humanista independente, mas "evitar que o Estado apoie uma confissão (cristã) em detrimento de outra ao apelar para o que todas elas compartilham" (Hurd, 2007: 41). Esse tipo de secularismo também se abstrai em teoria, e pode ser encontrado na "leitura protestante celebratória da modernidade que vai dos Escritos Teológicos de Hegel, passando pelo eixo Weber-Troeltsch e chegando até a interpretação de Talcot Parsons sobre as sociedades modernas como a institucionalização de princípios cristãos" (Casanova, 2008: 21). Hirschkind (2008) destaca a coincidência temporal entre o crescimento demográfico de minorias mulçumanas na Europa e o reforço de narrativas excepcionalistas sobre a "civilização judaico-cristã" tanto entre acadêmicos liberais (como Gauchet, Zizek e Nancy) quanto entre setores conservadores.

Apesar de produtivo, o modelo binário defendido por Hurd ainda é extremamente familiar, remetendo à tradicional oposição França/Estados Unidos da América. Esse universo comparativo tem-se ampliado com a inclusão de casos que transcendem o Atlântico Norte. Estados pós-coloniais como o Egito apresentam formas híbridas: o islã é sua religião oficial, mas a sharia é efetiva somente no direito familiar dos cidadãos que professam essa fé, o que submete a sua jurisdição à divisão liberal ente público e privado. A liberdade de crença de minorias religiosas é assegurada por uma justaposição entre o princípio islâmico de tolerância com as outras "religiões do Livro" (judaísmo e cristianismo) e a noção liberal de liberdade de consciência, o que gera tensões estruturais (Mahmood, 2016).

Giumbelli (2008) demonstra como, no Brasil, a destituição do catolicismo do posto de religião oficial em 1890 foi seguida por sua ascensão a modelo normativo genérico. Tal processo obrigou outras tradições a se adaptarem mimeticamente, por exemplo, através do foco legitimador na "caridade" ou no modelo associativo de igreja. Religiões de matriz africana, por sua vez, foram perseguidas através de leis relativas à magia e curandeirismo, práticas que se contrapunham à ordem pública, logo cuja repressão não contradizia o princípio constitucional da liberdade religiosa. Esse processo é complexificado pela adição de uma vertente "diferencial" de legitimação, que reacomoda esses grupos à sociedade civil através das políticas 
da cultura. A emergência tardia do cristianismo evangélico, por sua vez, representaria não apenas a insurgência de um novo grupo religioso, mas uma reformulação estrutural da relação entre religião, sociedade civil e Estado nacional (Montero, 2006).

Nota-se que os secularismos egípcio e brasileiro podem ser pensados como variações formalmente similares ao paradigma do "secularismo judaico-cristão”. Assim como este, eles são ideologias religioso-seculares, apesar de suas secularidades serem predicadas em matrizes alternativas, como o islã e o catolicismo. O mesmo pode se dizer da Índia, outro caso largamente estudado, cuja secularidade teria sido moldada através da reconfiguração do hinduísmo por intelectuais nacionalistas dos séculos XIX e XX em uma matriz cultural englobante ("filosofia"), apta a acomodar-se a uma variedade de religiões majoritárias e minoritárias. Alheio aos problemas do laicismo, como a privatização da religião, o secularismo indiano estaria preocupado, desde sua origem pós-colonial, com o "pluralismo religioso como um valor positivo combinado com a afirmação da unidade nacional dentro de um enquadramento democrático" (Madan, 2010: 184). Bhargava (2010) destaca as continuidades entre o secularismo indiano e seu passado pré-colonial, sugerindo que "enquanto os europeus aprenderam a ideia de tolerância com relação a outras seitas cristãs a partir da sua própria experiência, o espaço conceitual para a ideia da imparcialidade de todas as fés" (ibidem: 174) apareceu primeiro na Índia.

Hasan (2010), por sua vez, destaca as estratégias verticais de regulação e reforma secular do religioso pelo Estado indiano, como as leis que aboliram a intocabilidade e o casamento infantil e que reconheceram o direito de família islâmico entre essa comunidade minoritária. Mais do que uma emanação do passado, o pluralismo secular indiano seria marcado por uma interminável série de "atos de contrabalanceamento" (ibidem: 208) predicados em uma gramática cívica que refrata princípios e valores locais através de lentes liberais e republicanas herdadas do colonialismo, incluindo suas tensões e paradoxos. ${ }^{5}$ Por fim, a tensão longeva entre o secularismo indiano e o nacionalismo hindu, que hoje chega a um novo ponto de ebulição (Ahmad e Kanungo, 2019), demonstra que o trabalho acadêmico de tipificar secularismos não pode evitar o fato de estarmos lidando com um campo de forças dinâmico, que agrega dimensões religiosas, intelectuais, jurídicas e políticas.

O fim da hegemonia da teoria da secularização tem encorajado um olhar mais cuidadoso sobre secularismos não-ocidentais, projeto ainda

\footnotetext{
5 Veja-se Mani (1998) e Jenkins (2008).
} 
em curso (Barragán e Blancarte, 2016; Engelke, 2015). Outra consequência tem sido um olhar mais situado sobre a própria Europa, cuja secularidade permanece inconteste, apesar da existência de Estados com igrejas oficiais - como a Inglaterra, a Escócia, a Grécia e países escandinavos. Quase todos os Estados europeus com separação formal da Igreja mantêm uma série de vínculos contratuais mais duradouros com determinadas corporações religiosas, principalmente nos campos da educação, saúde e patrimônio cultural, incluindo a França-modelo do paradigma laicista. A legitimidade desses vínculos depende da divisão maioria/minoria, logo varia de acordo com a responsividade a transformações étnicas e religiosas recentes. É importante notar que valores liberais-democráticos como pluralismo religioso raramente coincidem com modelos específicos de secularismo e podem ser mais enfatizados em contextos com igrejas estabelecidas, como na Inglaterra, do que em contextos mais adequados ao conceito formalista de separação entre Estado e Igreja, como a França. Indiferente do contexto (europeu ou pós-colonial), a definição de secularismo enquanto "neutralidade do Estado com relação à religião" torna-se difícil de defender. Casanova (2008: 111) admite que "[s]e olharmos para a realidade das democracias europeias 'realmente existentes' e não para o discurso secularista oficial, torna-se óbvio que a ampla maioria dos Estados europeus não são estritamente seculares, e estão longe do mito da neutralidade secular".

De acordo com Mahmood (2016:3), o secularismo é "o poder soberano do Estado moderno de reorganizar traços substantivos da vida religiosa, estipulando o que a religião é ou deve ser, designando seu conteúdo próprio e disseminando subjetividades, enquadramentos éticos e práticas quotidianas concomitantes”. Com base nessa definição, podemos assumir que a separação formal ou não entre Estado e Igreja nunca implicará neutralidade com relação à religião, já que o secularismo político é um regime regulatório. O secularismo inclui uma dimensão pragmática indelével, dado seu uso político como categoria discursiva apta a produzir cortes entre "nós" e "eles", civil e incivil, seja no governo doméstico de minorias (Fernando, 2014), seja na promoção de intervenções geopolíticas (Mahmood, 2006; Reinhardt, 2011). Como destaca Asad (2003), tensões classificatórias não devem ser julgadas a partir de um protótipo ideal de secularidade neutra, mas examinadas como resultado da interdependência normativa entre o religioso e o secular. Esse fato torna os secularismos realmente existentes também inerentemente contingentes.

\section{Controvérsias e incomensurabilidades}

O segundo conjunto de estudos que gostaria de destacar tende a se concentrar nas controvérsias que explicitam tanto os pressupostos ontológicos da 
secularidade quanto suas tensões estruturais. A associação necessária entre secularismo político e soberania não deve implicar uma visão rígida do poder secular. De acordo com Agrama (2010), são exatamente as indeterminações de noções jurídicas como público/privado, religião/não-religião, e a predicação de conceitos como "ordem pública" na lógica da maioria/ /minoria que levantam incessantemente a questão dos limites entre religião e política na era secular, convidando o Estado a intervir. O secularismo seria uma ordem inerentemente controversa: conflitos particulares não atualizam estruturas prévias, mas "fazem" o secular (e o religioso). Montero (2012: 178; itálico no original) destaca as tensões entre essa abordagem e o modelo estático do "campo religioso" consagrado por Bourdieu: "O conceito de controvérsia nos permite observar as manipulações de diversas formas discursivas por diferentes agentes sem a necessidade de supor que eles estão todos disputando no interior de um mesmo campo e que manejam visões de mundo de um só campo".

Esse aspecto eventualmente aparece com ares cômicos. Em uma contenda jurídica recente na Califórnia, nos Estados Unidos da América (EUA), um cidadão processou seu empregador por infringir sua liberdade religiosa de "ateu adorador do Sol". ${ }^{6}$ Ele alegou que, ao obrigá-lo a trabalhar excessivamente, seu patrão impedia o cumprimento de seu dever religioso de dormir oito horas por dia. O estafado empregado jogou de forma jocosa com as várias decisões relativas à proteção da liberdade de religião aprovadas por cortes estaduais deste país ao longo dos anos: da poligamia mórmon, da ilegalidade de se obrigar testemunhas de Jeová a trabalhar aos sábados até medidas que permitam a empresas discriminar clientes LGBT ou que as obriguem a disponibilizar banheiros divididos por sexo. Apesar do surrealismo da demanda, o judiciário foi obrigado a produzir um conceito de religião (um "ismo") de modo a excluí-lo da proteção da lei. Argumentaram que o ateísmo adorador do Sol não "endereça questões fundamentais e últimas associadas a problemas profundos imponderáveis" (um apelo weberiano-geertziano à teodiceia) e seu ensinamento monocórdio sobre horas de sono não configura um "sistema de crenças" amplo o suficiente. Este caso inusitado demonstra que, seja para proteger, seja para proibir a religião, o Estado deve inevitavelmente objetificar práticas, valores, artefatos e deveres morais como tal, incluindo o ateísmo, cujos direitos são geralmente reclamados em termos de liberdade religiosa (Davis, 2005).

Em uma etnografia pioneira sobre a relação entre o judiciário e a religião, Sullivan (2005) detalha a ampla cadeia de autoridades (jurídicas, religiosas

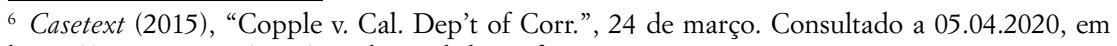
https://casetext.com/case/copple-v-cal-dept-of-corr. 
e acadêmicas) envolvidas na construção da religião nas cortes de justiça. Seu foco é um processo aberto por parentes de mortos reclamando sua liberdade religiosa de decorar os túmulos em contraposição às regulações de um cemitério da Flórida, nos EUA. A prática acaba sendo excluída da categoria de religião, logo, não protegida. Wenger (2009), por sua vez, explora os efeitos não-intencionais do próprio reconhecimento jurídico ao demonstrar como a inclusão jurídica da Dança do Sol dos índios pueblo na categoria de religião pelas cortes dos EUA serviu para protegê-la de intervenções policiais, mas às custas da perda da autonomia tribal deste povo.

Dinâmica similar replica-se nas controvérsias jurídicas acerca dos "símbolos religiosos" (Giumbelli, 2014). Observemos rapidamente o famoso caso Lautsi vs. Itália (Beaman, 2015), um processo aberto em 2011 por uma cidadã italiana de origem islandesa na Corte Europeia de Direitos Humanos. O caso revela as indeterminações inerentes a dois princípios seculares assegurados pela legislação europeia: os direitos à "liberdade de pensamento, consciência e religião" e a "manifestar crenças religiosas". Lautsi alegou que a exposição compulsória de crucifixos nas escolas públicas italianas causava dano à liberdade de consciência de seus filhos, evocando o princípio da liberdade de consciência. Em uma corte de primeira instância, os crucifixos foram qualificados como "emocionalmente perturbadores para alunos não-cristãos ou sem religião", logo contrariavam as "convicções seculares" dos indivíduos em questão (ibidem). Após recurso, no entanto, a corte máxima da União Europeia classificou os crucifixos como "símbolos essencialmente passivos", ou seja, que não afetavam o foro interno dos alunos como o fariam outras manifestações abertamente religiosas como "o discurso didático ou a participação em cerimónias religiosas" (ibidem).

Um ponto a ser destacado é como, na prática jurídica, a noção de símbolo opera como uma dobradiça entre dimensões privada e pública, religiosas e seculares, o que permite ao Estado estabelecer a própria topografia do sujeito liberal. O caso demonstra que, ao invés de pertencer a um dos polos de uma oposição de tipo civilizatório entre self poroso e insulado - como quer Taylor (2007) -, o poder secular opera através de uma pragmática da subjetivação que oscila entre porosidade e insularidade de maneira seletiva e situada. Basta que cotejemos este caso com decisões da mesma corte europeia sobre os casos Dahlab vs. Suíça ou Sahin vs. Turquia, em que o uso do véu islâmico por professoras em sala de aula foi considerado "um símbolo externo poderoso", proscrito de modo a "proteger as crenças religiosas dos estudantes e de seus pais e aplicar o princípio da neutralidade religiosa nas escolas" (Adrian, 2017: 176).

A normatividade protestante embutida no conceito secular de "símbolo religioso" é mais profunda do que a mera disposição a aceitá-los ou 
proscrevê-los. Mahmood (2005) demonstra como a incomensurabilidade entre as visões seculares (laicistas ou pluralistas) e islâmicas acerca do véu estaria justamente no uso da noção secular-protestante de "símbolo" para definir um objeto que é operacionalizado na prática devocional através da lógica encorporada [embodied] que caracteriza a ética da virtude (MacIntyre, 1984). A relação entre o véu e virtudes islâmicas prescritivas, como a modéstia, não é simbólica ou representacional, mas teleológica. Mahmood (2005) apresenta a devoção das mulheres muçulmanas que etnografou no Egito através de um modelo de habilitação ética: o véu não "medeia" ou "simboliza" a virtude da modéstia, ele é parte constitutiva de um modo de vida em que a modéstia emerge como uma habilidade corpórea desejável, parte material essencial de práticas que visam justamente apagar a divisão entre "foro interno" e "externo" através da formação de um babitus virtuoso.

Mahmood (2009) mobiliza método similar em sua análise da controvérsia em torno das representações satíricas do profeta Mohammed publicadas na Dinamarca. Por um lado, os patronos da "liberdade de expressão" estabeleceram que a crença é ontologicamente distinta de suas manifestações materiais. Logo, caberia aos próprios muçulmanos entender que o foro externo é regido pela livre circulação e apropriação de imagens e que isso não afeta o foro interno da consciência religiosa. Por outro lado, a noção de crença também colocou os muçulmanos como alheios ao direito de criticar, já que, "diferente das crenças religiosas, a crítica é baseada em um necessário distanciamento entre sujeito e objeto e alguma forma de deliberação racional" (ibidem: 861). De acordo com Mahmood, a separação kantiana radical entre reflexividade racional crítica e lealdade metafísica, institucional e afetiva (Connolly, 1999), que caracteriza a secularidade europeia, "não apenas caricatura o outro religioso, mas, mais importante, permanece cega às suas próprias disciplinas de subjetividade, apegos afetivos, e relações sujeito/objeto" (Mahmood, 2009: 861). Mesmo aqueles que se opuseram aos cartoons e os acusaram de racismo perderam de vista a semiótica específica que estruturou a ferida moral muçulmana: uma relação não-simbólica com a figura do profeta, próximo ao modelo aristotélico da schesis, que pressupõe formas de coabitação afetiva e relacionalidade corpórea com a imagem exemplar. Uma perspectiva mais cuidadosa e imanente sobre a imagem no islã, portanto, acaba por revelar a proximidade entre ideologias semióticas liberais e cristãs protestantes, incluindo o primado saussuriano do "arbitrário do signo" (Keane, 2007).

A análise simétrica de controvérsias, como as oferecidas por Mahmood $(2005,2009)$, revela aspectos internos às tradições religiosas que permanecem irredutíveis à representação secular da religião. Talvez mais importante, 
as controvérsias também explicitam a estrutura normativa que regula a própria participação na esfera pública secular. Elas mostram que, diferente de um espaço vazio e neutro para a deliberação, a esfera pública é constituída pelas "sensibilidades - memórias e aspirações, medos e esperanças - daqueles que nela se comunicam" (Asad, 2003: 185). Sua racionalidade comunicativa universalista é devedora das relações de poder assimétricas que vieram a estabelecer no tempo seus protocolos de percepção e mediação (Hirschkind, 2006; Warner, 2016).

\section{Viradas, paradigmas, problematizações}

De acordo com Casanova (1994: 17), a secularização talvez tenha sido "a única teoria capaz de assumir um caráter verdadeiramente paradigmático dentro das ciências sociais modernas". Saler (2006: 710), por sua vez, qualifica a influência longeva da teoria do desencantamento nas ciências sociais como um encanto paradigmático que "parece estar se quebrando". O que resta depois da crise de hegemonia desses modelos tão englobantes?

Em seu livro seminal, Thomas Kuhn (1998: 225) utilizou o termo paradigma em pelos menos dois sentidos complementares: como "constelações dos compromissos de grupo" desenvolvidas por comunidades científicas em redes de colaboração, citação e crítica; e como "exemplos compartilhados", modelos que estabilizam as orientações perceptivas de um grupo (ibidem: 232). Essa perspectiva dupla permite a Kuhn recolocar a história da ciência em termos de avanços acumulativos pontuados por incomensurabilidades, considerando que paradigm shifts operam em escala linguística e metalinguística: "O que fez Einstein: mostrou que a simultaneidade era relativa ou alterou a própria noção de simultaneidade?” (ibidem: 228).

Ignorando por ora o debate em torno da aplicabilidade da epistemologia kuhniana às ciências humanas, acredito que a virada crítico-reflexiva nos estudos da religião e do secularismo contém fortes traços paradigmáticos. Sua pauta comum é reflexo de redes concretas de comunicação, crítica e citação, além de comprometimentos de base, como a revisão do cânone e a transfiguração reflexiva da secularidade de horizonte para tema de investigação. Autores como Asad visam uma reorientação geral da Gestalt acadêmica em torno de categorias como "religião" e seus termos cognatos. Como destaquei, isso se dá através de uma escavação genealógica, que explicita os vínculos normativos entre as ciências sociais e a secularidade ocidental, e de uma abordagem pragmática para as contingências dos secularismos enquanto formas de regulação do sensível. Por fim, apesar de não raramente receber a alcunha de "virada pós-secular", o que chamei de estudos críticos da religião e do secularismo abrange uma variedade de viradas, 
o que atestaria sua dimensão paradigmática. A crítica ao conceito mentalista de crença, por exemplo, estimulou abordagens para a diferença religiosa que intersectam com a virada material (Engelke, 2012), a virada ética (Fassin, 2012), a virada ontológica (Bialecki, 2014) e a virada pós-colonial (Loyd e Viefhues-Bailey, 2015). Se a teoria da secularização adquiriu um status paradigmático no passado, sua desconstrução só poderia ter efeitos extensos, a ponto de Smith (2011: 176) afirmar que qualquer modalidade de pós-fundacionalismo em teria social hoje "implica pós-secularismo".

Procurei demonstrar, no entanto, que o trabalho de Asad não visa simplesmente redirecionar o aparato conceitual das ciências sociais para uma nova cathexis estável. Diferente de Casanova ou Taylor, a vertente asadiana da antropologia do secularismo opera a partir do conceito dinâmico de crítica que Foucault (2004) denomina problematização. Ao definir o religioso e o secular sobretudo como espaços-problema, Asad indica que o objetivo de sua antropologia não seria a representação de um objeto preexistente, mas a recuperação reflexiva do "conjunto de práticas discursivas e não-discursivas que fazem com que algo entre no jogo do verdadeiro e do falso e o constituam como um objeto para o pensamento" (Foucault, 2004: 242). Operando entre método e objeto, e reconhecendo o entrelaçamento entre o teórico e o moral, problematizações emergem sobretudo de "situações" - no caso em questão, uma crise em nossos conceitos e sensibilidades adquiridos sobre o lugar e os limites próprios à religião. A problematização busca facilitar uma mudança modal na situação ou nas situações que a convidaram, de modo que elas parem de ser vistas como dados e passem a ser vistas como uma constelação de questões.

Mahmood caminha nesta direção quando, depois de demonstrar os emaranhamentos entre secularidade e conflito religioso no Egito colonial e pós-colonial - o que em si falsearia os argumentos sobre a secularização como panaceia para todos males -, conclui perguntando-se se "a ideia de igualdade entre as fés pode requerer não a suspensão das diferenças religiosas, mas a sua tematização ética como um risco necessário quando os recursos políticos e conceituais do Estado se provam inadequados ao desafio que este ideal coloca diante de nós" (Mahmood, 2016: 213; itálico no original). Essa empreitada implica pensar a produtividade política de conceitos ortodoxos não apenas em seu contraste com uma tradição liberal visivelmente esgarçada, mas também em seu próprio potencial para o florescimento humano. É o que demonstra Asad (2017: 363) em sua análise do conceito de amr bi-l-ma'rúf (exortar o que é correto e opor-se ao que é repreensível) como "uma tradição religiosa que autoriza a promoção de virtudes relevantes ao nível político" ou Hirschkind (2008) em seus comentários sobre as alianças 
cidadãs entre mulçumanos e coptas em torno do conceito de dhimmi (minoria não-mulçumana protegida) no Egito. Trabalhos similares, aptos a desestabilizar os vínculos entre evangelicalismo e neoconservadorismo sectário restam a ser realizados (cf. Reinhardt, 2020). Uma de suas condições de possibilidade é o abandono de abordagens culturalistas ou funcionais para o que de fato são "ressonâncias" hegemônicas, mas contingentes, entre forças religiosas e seculares (Connolly, 2008).

Diferente de uma adequação teórica a uma nova realidade, a problematização visa ampliar as articulações reais e virtuais entre formas de conhecimento, matrizes normativas de comportamento, e modos de existência. Ela assume que objetos como "a religião" são sobretudo "tipos interativos" (Hacking, 2000), acessados em meio a eventos de representação e intervenção, e não "tipos naturais", mais recalcitrantes e relativamente indiferentes às dimensões morais e políticas das práticas de definição.

Unidas na obra de Asad, a antropologia, a genealogia e a pragmática adquirem o teor sistemático e extenso de um paradigma justamente ao problematizar - logo, não deixar sedimentar-se de maneira hegemônica a sua qualidade mais definitiva: a própria historicidade. Assim, uma antropologia do secularismo só pode ser uma antropologia do tempo ele mesmo, incluindo os mundos possíveis que a secularidade viabiliza e aborta.

Revisto por Ana Sofia Veloso

\section{Referências bibliográficas}

Adrian, Melanie (2017), "The Principled Slope: Religious Freedom and the European Court of Human Rights”, Religion, State \& Society, 45(3-4), 174-185.

Agrama, Hussein (2010), "Secularism, Sovereignty, Indeterminacy: Is Egypt a Secular or a Religious State?", Comparative Studies in Society and History, 52(3), 495-523. Ahmad, Irfan; Kanungo, Pralay (orgs.) (2019), The Algebra of Warfare-Welfare: A Long View of India's 2014 Elections. Delhi: Oxford University Press.

Asad, Talal (1993), Genealogies of Religion: Discipline and Reasons of Power in Christianity and Islam. Baltimore: Johns Hopkins University Press.

Asad, Talal (2003), Formations of the Secular: Christianity, Islam, Modernity. Stanford: Stanford University Press.

Asad, Talal (2006), "Response to Casanova”, in David Scott; Charles Hirschkind (orgs.),

Powers of the Secular Modern: Talal Asad and His Interlocutors. Stanford: Stanford University Press, 207-210.

Asad, Talal (2012), "Thinking about Religion, Belief, and Politics”, in Robert Orsi (org.), The Cambridge Companion to Religious Studies. Cambridge: Cambridge University Press, 36-57. 
Asad, Talal (2017), "Pensando sobre tradição, religião e política no Egito contemporâneo”, Política \& Sociedade, 16(36), 347-402. Tradução de Jorge Botelho Moniz [orig. 2015].

Atiemo, Abamfo O. (2013), Religion and the Inculturation of Human Rights in Ghana. London: Bloomsbury.

Barragán, José; Blancarte, Roberto J. (2016), "Secularism and Secularization”, in Virginia Garrard-Burnett; Paul Freston; Stephen Dove (orgs.), The Cambridge History of Religions in Latin America. Cambridge: Cambridge University Press, 331-345.

Beaman, Lori (2015), "Freedom of and Freedom from Religion: Atheist Involvement in Legal Cases”, in Lori Beaman; Steven Tomlins (orgs.), Atheists Identities: Spaces and Social Contexts. London: Springer, 39-52.

Berger, Peter (1999), The Desecularization of the World: Resurgent Religion and World Politics. Grand Rapids, MI: Ethics and Policy Center.

Bhargava, Rajeev (2010), “The 'Secular Ideal' Before Secularism: A Preliminary Sketch”, in Linell Cady; Elizabeth Hurd (orgs.), Comparative Secularisms in a Global Age. New York: Palgrave Macmillan, 159-180.

Bialecki, Jon (2014), "Does God Exist in Methodological Atheism? On Tanya Lurhmann's When God Talks Back and Bruno Latour", Antbropology of Consciousness, 25(1), 32-52.

Brown, Wendy (2006), Regulating Aversion: Tolerance in the Age of Identity and Empire. New Jersey: Princeton University Press.

Calhoun, Craig (2012), "Time, World, and Secularism”, in Philip S. Gorski; David Kyuman Kim; John Torpey; Jonathan VanAntwerpen (orgs.), The Post-Secular in Question: Religion in Contemporary Society. New York: New York University Press, 335-364.

Cantwell-Smith, Wilfred (2006), O sentido e o fim da religião. São Leopoldo: Sinodal. Tradução de Geraldo Korndörfer [orig. 1964].

Casanova, José (1994), Public Religions in the Modern World. Chicago: The University of Chicago Press.

Casanova, José (2008), "Public Religions Revisited”, in Hent de Vries (org.), Religion. Beyond a Concept. Fordham: Fordham University Press, 101-119.

Chakrabarty, Dipesh (2000), Provincializing Europe: Postcolonial Thought and Historical Difference. Princeton: Princeton University Press.

Chatterjee, Nandini (2010), "English Law, Brahmo Marriage, and the Problem of Religious Difference: Civil Marriage Laws in Britain and India”, Comparative Studies in Society and History, 52(3), 524-552.

Chatterjee, Partha (2006), "Fasting for Bin Laden: The Politics of Secularization in Contemporary India”, in David Scott; Charles Hirschkind (orgs.), Powers of the Secular Modern: Talal Asad and His Interlocutors. Stanford: Stanford University Press, 57-74. 
Chidester, David (1996), Savage Systems: Colonialism and Comparative Religion in Southern Africa. Charlottesville: University Press of Virginia.

Comaroff, Jean; Comaroff, John L. (1997), Of Revelation and Revolution, Volume 2: The Dialectics of Modernity on a South African Frontier. Chicago: University of Chicago Press.

Connolly, William (1999), Why I Am Not a Secularist. Minneapolis: University of Minnesota Press.

Connolly, William (2008), Capitalism and Christianity, American Style. Durham: Duke University Press.

Davis, Derek H. (2005), "Is Atheism a Religion? Recent Judicial Perspectives on the Constitutional Meaning of 'Religion'”, Journal of Church and State, 43(4), 707-723.

DeCerteau, Michel (1992), The Writing of History. New York: Columbia University Press.

Dubuisson, Daniel (2003), The Western Construction of Religion. Baltimore: Johns Hopkins University Press.

Engelke, Matthew (2012), "Material Religion”, in Robert A. Orsi (org.), The Cambridge Companion to Religious Studies. Cambridge: Cambridge University Press, 209-229.

Engelke, Matthew (2015), "Secular Shadows: African, Immanent, Post-Colonial”, Critical Research on Religion, 3(1), 86-100.

Fassin, Didier (org.) (2012), A Companion to Moral Antbropology. Malden: Wiley-Blackwell.

Fernando, Mayanthi (2014), The Republic Unsettled: Muslim French and the Contradictions of Secularism. Durham: Duke University Press.

Foucault, Michel (2004), "O cuidado com a verdade”, in Manuel Motta (org.), Ditos e escritos, vol. V. Rio de Janeiro: Forense Universitária, 234-245. Tradução de Elisa Monteiro e Inês Autran Dourado Barbosa [orig. 1994].

Frei, Hans W. (1974), The Eclipse of Biblical Narrative: A Study in Eighteenth and Nineteenth Century Hermeneutics. New Haven: Yale University Press.

Geertz, Clifford (1989), A interpretação das culturas. Rio de Janeiro: LTC. Tradutor não informado [orig. 1973].

Giumbelli, Emerson (2008), “A presença do religioso no espaço público: modalidades no Brasil”, Religião e Sociedade, 28(2), 80-101.

Giumbelli, Emerson (2014), Símbolos religiosos em controvérsias. São Paulo: Terceiro Nome.

Göle, Nilüfer (2010), "Manifestations of the Religious-Secular Divide: Self, State and the Public Sphere”, in Linell Cady; Elizabeth Shakman Hurd (orgs.), Comparative Secularisms in a Global Age. New York: Palgrave Macmillan, 41-56.

Gorski, Philip; Kim, David; Torpey, John; VanAntwerpen, Jonathan (orgs.) (2012), The Post-Secular in Question: Religion in Contemporary Society. New York: New York University Press. 
Habermas, Jürgen (2007), Entre naturalismo e religião: estudos filosóficos. Rio de Janeiro: Tempo Brasileiro. Tradução de Flávio Beno Siebeneichler [orig. 2005].

Hacking, Ian (2000), The Social Construction of What? Cambridge: Harvard University Press.

Hasan, Zoya (2010), "Not Quite Secular Political Practice", in Cady Linell; Elizabeth Shakman Hurd (orgs.), Comparative Secularisms in a Global Age. New York: Palgrave Macmillan, 197-215.

Hayes, Carlton (1960), Nationalism: A Religion. New York: Macmillan Company.

Hirschkind, Charles (2006), The Ethical Soundscapes: Cassette Sermons and Islamic Counterpublics. New York: Columbia University Press.

Hirschkind, Charles (2008), "Religious Difference and Democratic Pluralism: Some Recent Debates and Frameworks", Temenos, 44(1), 123-138.

Hurd, Elizabeth (2007), The Politics of Secularism in International Relations. Princeton: Princeton University Press.

Jenkins, Laura (2008), "Legal Limits on Religious Conversion in India”, Law and Contemporary Problems, 71, 109-127.

Keane, Webb (2007), Christian Moderns: Freedom and Fetish in the Mission Encounter. Berkeley: University of California Press.

Koselleck, Reinhard (2014), Estratos do tempo: estudos sobre bistória. Rio de Janeiro: Contraponto. Tradução de Markus Hediger [orig. 2007].

Krasner, Stephen (1999), Sovereignty: Organized Hypocrisy. Princeton: Princeton University Press.

Kuhn, Thomas (1998), A estrutura das revoluções cientificas. São Paulo: Perspectiva. Tradução de Beatriz Vianna Boeira e Nelson Boeira [orig. 1962].

Lefort, Claude (1991), "Permanência do teológico-político?", in Pensando o Político: Ensaios sobre Democracia, Revolução e Liberdade. Rio de Janeiro: Paz e Terra, 249-295. Tradução de Eliana de Melo Souza [orig. 1962].

Lloyd, Vincent William; Viefhues-Bailey, Ludger (2015), "Introduction: Is the Postcolonial Postsecular?", Critical Research on Religion, 3(1), 13-24.

Locke, John (2014), Carta sobre a tolerância. Rio de Janeiro: Edições 70. Tradução de Anoar Aiex [orig. 1689].

Löwith, Karl (1990), O sentido da história. Rio de Janeiro: Edições 70. Tradução de Maria Georgina Segurado [orig. 1949]

Luehrmann, Sonja (2011), Secularism Soviet Style: Teaching Atheism and Religion in a Volga Republic. Bloomington: Indiana University Press.

MacIntyre, Alasdair (1984), After Virtue: A Study in Moral Theory. Notre Dame, IN: University of Notre Dame Press.

Madan, Triloki (2010), "Indian Secularism: A Religious-Secular Ideal”, in Linell Cady; Elizabeth Hurd (orgs.), Comparative Secularisms in a Global Age. New York: Palgrave Macmillan, 181-196. 
Mahmood, Saba (2005), Politics of Piety: The Islamic Revival and the Feminist Subject. Princeton: Princeton University Press.

Mahmood, Saba (2006), "Secularism, Hermeneutics, and Empire: The Politics of Islamic Reformation”, Public Culture, 18(2), 323-347.

Mahmood, Saba (2009), "Religious Reason and Secular Affect. An Incommensurable Divide?”, Critical Inquiry, 35, 836-862.

Mahmood, Saba (2016), Religious Difference in a Secular Age: A Minority Report. Princeton: Princeton University Press.

Mamdani, Mahmood (1996), Citizen and Subject: Contemporary Africa and the Legacy of Late Colonialism. Princeton: Princeton University Press.

Mani, Lata (1998), Contentious Traditions: The Debate on Sati in Colonial India. Berkeley: University of California Press.

Masuzawa, Tomoko (2005), The Invention of World Religions: Or, How European Universalism Was Preserved in the Language of Pluralism. Chicago: The University of Chicago Press.

McClure, Kirstie (1990), "Difference, Diversity, and the Limits of Toleration”, Political Theory, 18(3), 361-391.

Milbank, John (2006), Theology and Social Theory: Beyond Secular Reason. Oxford: Blackwell.

Montero, Paula (2006), "Religião, pluralismo e esfera pública no Brasil”, Novos Estudos CEBRAP, 74, 47-65.

Montero, Paula (2012), "Controvérsias religiosas e esfera pública: repensando as religiões como discurso", Religião e Sociedade, 32(1), 167-183.

Nongbri, Brent (2013), Before Religion: A History of a Modern Concept. New Haven: Yale University Press.

Proudfoot, Wayne (1985), Religious Experience. Berkeley: University of California Press.

Reinhardt, Bruno (2011), "Reiterando o pacto: história, teologias políticas cristãs e a religião civil americana em uma era de multiculturalismo e império”, Religião \& Sociedade, 31(2), 29-54.

Reinhardt, Bruno (2020), “Emergent Atlantics: Black Evangelicals' Quest for a New Moral Geography in Salvador, Bahia, Brazil”, in Markus Balkenhol; Ruy Blanes; Ramon Sarró (orgs.), Atlantic Perspectives: Places, Spirits and Heritage. Oxford: Berghahn, 92-110.

Robbins, Joel (2003), "What Is a Christian? Notes Toward an Anthropology of Christianity”, Religion, 33(3), 191-199.

Saler, Michael (2006), "Modernity and Enchantment: A Historiographic Review”, American Historical Review, 111(3), 692-716.

Schmitt, Carl (1996), Teologia política: quatro capítulos sobre a doutrina da soberania. São Paulo: Scritta. Tradução de Elisete Antoniuk [orig. 1922].

Schwab, Raymond (1984), The Oriental Renaissance: Europe's Rediscovery of India and the East, 1680-1880. New York: Columbia University Press. 
Sharf, Robert (1998), "Experience”, in Mark Taylor (org.), Critical Terms for Religious Studies. Princeton: Princeton University Press, 94-116.

Shaw, Rosalind (1990), "The Invention of 'African Traditional Religion'”, Religion, 20(4), 339-353.

Simpson, James (2007), Burning to Read: English Fundamentalism and Its Reformation Opponents. Cambridge, MA: Harvard University Press.

Smith, James K. A. (2011), "Secular Liturgies and the Prospects for a 'Post-Secular' Sociology of Religion", in Philip S. Gorski; David Kyuman Kim; John Torpey; Jonathan VanAntwerpen (orgs.), The Post-Secular in Question: Religion in Contemporary Society. New York: New York University Press, 159-184.

Sullivan, Winnifred (2005), The Impossibility of Religious Freedom. Princeton: Princeton University Press.

Taylor, Charles (1998), "Modes of Secularism”, in Rajeev Bhargava (org.), Secularism and Its Critics. Oxford: Oxford University Press, 31-53.

Taylor, Charles (2007), A Secular Age. Cambridge: Harvard University Press.

van der Veer, Peter (1994), Religious Nationalism: Hindus and Muslims in India. Berkeley: University of California Press.

van der Veer, Peter (2009), "Spirituality in Modern Society", Social Research, 76(4), 1097-1120.

Warner, Michael (2016), "Públicos e contrapúblicos (versão abreviada)", Periódico Permanente, 6, 1-17. Tradução de Ethiene Nachtigall [orig. 2002].

Wenger, Tisa (2009), We Have a Religion: The 1920s Pueblo Indian Dance Controversy and American Religious Freedom. Chapel Hill: University of North Carolina Press.

Artigo recebido a 03.06.2020

Aprovado para publicação a 10.08 .2020

\section{Bruno Reinhardt}

Departamento de Antropologia e Programa de Pós-graduação em Antropologia Social, Centro de Filosofia e Ciências Humanas, Universidade Federal de Santa Catarina

Campus Universitário Reitor João David Ferreira Lima - Trindade, Florianópolis - Santa Catarina, CEP 88040-900, Brasil

Contacto: bmnreinhardt@gmail.com

ORCID: https://orcid.org/0000-0003-3853-5927 


\section{The Critical Studies of Religion and Secularism: Turn or Paradigm?}

The article proposes a review, based on the work of Talal Asad, of the critical turn in the studies of religion and secularism. I revisit some aspects of Asad's genealogical and anthropological approach to religion, the secular, and secularism, and address two lines of research it has encouraged: the comparative study of actually existing secularisms and the symmetrical study of frictions and controversies between the secular concept of religion and the traditions it encompasses. I conclude by debating whether the recent realignment of religion in secular scholarship would indicate a "turn" or a "paradigmatic shift". Keywords: critical studies of religion; political power and religion; secularism; Talal Asad.

\section{Les études critiques de la religion et de la sécularisation : tournant ou paradigme?}

Dans cet article, je propose une révision du récent tournant critique dans les études de la religion et de la sécularisation. Je revisite certains aspects de l'approche généalogique et anthropologique de Talal Asad en matière de religion, de séculaire et de sécularisation, et je souligne deux axes de recherche qu'elle a encouragés : l'étude comparative des sécularisations réellement existantes et l'étude symétrique des frictions et des controverses entre le concept séculaire de religion et les traditions qu'elle englobent. Ce survol servira de base pour débattre la question de savoir si le récent réaménagement de la place de la religion dans le milieu universitaire indiquerait un « tournant » ou un « changement paradigmatique ».

Mots-clés: études critiques de la religion; pouvoir politique et religion; sécularisation; Talal Asad. 